\title{
Research of Teaching Mode Based on Art Design Major
}

\author{
Xiaorong Zhu \\ School of Art and Design of Eastern Liaoning University, Dandong, Liaoning, China \\ zxr_550@163.com
}

\begin{abstract}
In this project, there are three teaching modes based on art and deign professional teaching in college. These are "scaffolding", "remote control" and "drift bottle" Analysis these teaching mode realization during teaching process. Education is servicing to students. Students are the main point of education. Teacher's role is to inspire and guide. Both teachers and students are explorers, learners and researchers. The teaching process is an open dynamic teaching mode.
\end{abstract}

Keywords - Drift bottle, remote control, scaffolding

\section{Introduction}

Teaching mode has directivity and operability. Teaching philosophy has decided the teaching mode. A concrete expression of the teaching model is the basic framework of the curriculum system and teaching program implementation [1]. Aim at the concrete characters of art design speciality, a discussion on execution process of teaching is given in following teaching model, for reference only.

\section{Scaffolding Teaching Mode}

Scaffolding refers to the construction site for the construction and erected vertical and horizontal transport and construction bracket. Use "scaffolding" nouns image the descriptive art design class professional foundation courses learning phase teaching status, in short, the teachers based on the actual situation of the students to build the "scaffolding" to adapt to different learning objectives, step-by-step through the scaffolding to guide students professional foundation courses, students learn to build along the teacher "scaffolding" within the planned time (teaching progress) rising to a higher level teaching objectives, including the teaching of the knowledge import scaffolding expertise scaffolding, scaffolding design performance three link.

\section{A. The Horizontal Scaffolding - knowledge Import}

This is an imported concept, clarify ideas, clear the parallel learning stage of learning objectives, teachers are the most important task is to convey to students a clear concept of knowledge and learning ideas, so that students know what is facing the learning goals? What kind of learning concept into the learning state [2]?

Diversified teaching methods can be used to achieve teaching objectives, such as classroom lectures to pass, which requires teachers to have high language skills, able to import courses according to students' cognitive level cognitive understanding and learning, so that students can also experience the interpretation under the guidance of teachers, to find the link between the cognitive structure of this course and related courses, and to foresee and prepare for the Next curriculum problems encountered; reality extensive experience in cases summarized as learning concepts and logic, and then infer the teaching objectives should be reached, this method of teaching organic and rationality of the real scene and achieve teaching objectives, learning is likely to arouse the subjective power.

\section{B. The Vertical Scaffolding - Professional Skills}

Professional skills-based courses teaching content is difficult, by constructing a vertical scaffolding "of course the vertical arrangement is broken down into a number of unit module, in order to gradually deepen the understanding of the course.

Began to build from the lowest platform close to the level of students' cognitive teaching "scaffolding", so that the students involved in the formation of self-construction, the potential ability of the independent inquiry and the development of students, teachers guide the timely prompts and continue to build in front of the new teaching "scaffolding" to help the students to rise to a higher level of knowledge framework module along the framework of the knowledge of the "scaffolding" gradually climb along. As already predicted level scaffolding - import stage "learning objectives, students' confidence and desire to help teachers" scaffolding "to complete the final course learning objectives.

\section{Comprehensive Scaffolding - Design Performance}

If teachers teach the concept and implementation of teaching methods is described as structures "scaffolding", then by scaffolding the role eventually students learn the meaning of design works, you can title as "designer". Every student is with a designer's dream came to college to learn to become a designer College of Art and Design professional pursuit of professional goals.

Art and design profession, professional design program is the professional goals in social applications can be implemented in accordance with the design requirements independently [3]. Achieve this goal needs to be upgraded to higher teaching philosophy and teaching requirements, need the complexity of a higher level, criss-cross, function more perfect "scaffold".

\section{Remote Control Teaching Model}

Meaning of the remote control is within a certain range of the steering control. For teaching meaning "remote control" is controlled by the teacher, to have put freely closing ability, "release" the students placed in a reality of the situation is basically the same or similar virtual teachers build learning scene, so the students on knowledge learned upcoming first for 
self-awareness and experience and the formation of the problem, "revenue" back control "revenue" recover student feedback [4]. Remote control teaching mode is that you want to play teachers teaching a leading role, but also to fully tap the students' subjective learning initiative to build teacherstudent interaction, teaching and learning atmosphere of harmonious communication, and in all aspects of the implementation of the teaching program implementation, teachers should remain " remote "the ability to reach the remote control teaching mode of teaching objectives [5].

Remote control-style teaching model suitable for the design stages of learning art and design professionals, students master the basic skills of the art design professional, selfdesign awareness, and began to try to combine technology and design art, real case for training object complete professional design, and then experience feelings of "designer". Remote control teaching model including self-experience, teaching ondemand, remote boot three teaching links.

\section{A. Independent Experience}

Design started in to find the problem and found that the problem is the entry point for the design, design thinking around specific issues. Most students found that awareness of the problem is quite weak, due to the impact of traditional indoctrination teaching ideas for students of art and design professional, you need to establish found that awareness of the issues and thinking problems [6].

In this part, the specific teaching program implementation is to build practical experience and self-learning scene for students, so that students get the full sense of the personal involvement of the imagination and exploration, designconscious mobilized into the state initiative to identify problems. Because the next phase of the study is full of selfchallenge to do to enter the teaching on-demand "link foreshadowing.

\section{B. Teaching on Demand}

This link is to guide the discovery teaching methods, the problem of learning and inquiry learning methods and stage [7]. The in teachers "remote" students 'cognitive and experience recovery and experience, teachers involved in the teaching guide to form interactive teaching to address students' questions, the process of inductive knowledge. At this time there should be enough wonderful teaching scripts for teachers and students on Demand enjoy. For example, a student independent practice summary experiential learning students to think independently completed passion and learn wisdom interpretation, face exciting answers to students' questions teachers, in-depth analysis of the teachers on practical projects or design works incisive speech summarized the essence and nature of the direct knowledge, these processes demonstrated in the multimedia teaching platform, Figure, tables, text, and Mao, a key part of the best image to enlarge the difficulty of the course knowledge, focus and knowledge framework To play in different ways and different angles of interpretation, so that the knowledge points more clear and easy to understand. Teachers that have free space awareness to the students to learn lessons from mistakes, but also to provide modest help and guide students, bungled students due to self-solve the frustrating problem lack the motivation to learn through their own experience, independent Thinking and expected in teacher incentive guided completed the teaching program implementation[7].

In a teaching scene, the teachers' control of the remote control, the chief of the scene presided over the decision when to play what teaching interactive programs, when to go to the next instruction execution link when ending, but also to guide and support students to guest host the common interpretation of the completion of the teaching program. These teaching methods will be abstract visualization of knowledge, not only for the students to understand and learn knowledge protection, but also improve the efficiency of the practice teaching, changing a the teachers single demonstration students to imitate the traditional forms, the formation of teaching interaction, and thereby stimulate interest in learning, reflect the personality of thinking, increase motivation, promote personality development.

\section{Remote Boot}

Solve real-world design applications is different from the scene and design jobs, school virtual reality design variability and uncertainty increases the difficulty of the problem-solving help active thinking, grasp the connotation and denotation of Art and Design, seize Design The essential part of school design job perfect realize a transformation of social design works[8].

Or more aspects of the learning experience to complete most of the teaching lectures task, on this basis, you can try to "put" owned by the students to the real social practice platform, close to the social practice of teachers assigned to complete the instructional design jobs, teachers "remote control" teaching in the form of personalized counseling, to achieve teaching objectives is to guide the students outside to the inside layers of progressive, step-by-step in-depth thinking to improve the ability of students of professional applications.

\section{The Drift Bottles Teaching Mode}

Since ancient times, the drift bottles to people across the vastness of the sea fun way to communicate, drift bottles thrown into the sea does not know will drift to where, who picked up, filled with unknown mysterious atmosphere. The drift bottles as a form of teaching mode, and no doubt is an open teaching mode, is a combat training design applications can be reached. In graduation design phase, students in the form of a drift bottles face contact with the community, social examination, whether it is excellent or inexperienced students are very necessary. Because the community is a school without walls, design complexity can not be artificially virtual Zhenti really do help to open up the horizons of the students cultivate the practical ability of students to design, improve the overall quality of students is the drift bottles teaching mode landing point [9].

Drift bottles teaching mode includes three teaching aspects of the job sign, drift bottles, soft landing. 


\section{A. Operating Signed}

Job signed is the job name and design topics.

The completion of these operations or design process is the important process of learning to deepen and sublimation. It is not a comprehensive summary of the students' professional learning and practical results is a comprehensive examination of the quality and ability of students .

\section{B. Drift Bottles}

Carrying students as operating signed the "drift bottles" on the social sea means that students in independent study and practice began, the students in the teachers guide independent to select professional practice platform, embarked on a design the division of the self-development of the road. Designers to go through professional knowledge, experience and practice of the three processes, broad social classroom to provide students with the grand plans of combat platforms, is received by the campus toward social drift bottles Art and Design to pursue a non- purpose, culture lyrical value unpredictable and can not be accurately measured, but the community with these mind filled with knowledge, but the lack of practice "drift bottles" With historical encounter will derive a period of mutual attachment to the job with employment Love. The rich professional potential drift bottles "social temper baptism, the ultimate success of integration into the vast ocean of the community.

\section{Soft Landing}

When the students after the prodigal son like design practice rafting regression in familiar college campuses, teachers and students gathered in an exchange social class experienced feelings and experiences, which runs through the happy, honest and rich emotional, teachers and students in thinking and emotion in professional understanding of the experience, students from perceptual to rational, constitutes the teaching of art and design integrity [10]. The final students finish college confident and relaxed attitude back to the community, they are no longer drift bottles, their emergence into a butterfly, is truly socially useful design talent.

\section{Conclusion}

The German educator the Andean multi noted and said: "The art of education is not to teach, but in incentives, wake up and encouraged."

Teaching mode based on the art of design professionals, teachers and students as explorers, learners and researchers, exploring, open and vibrant atmosphere for art and design professionals to build, to build a dynamic learning model, teacher-student interaction, so that The teaching process innovation.

Education services to students, the students are the subject of education, the teacher's role is to inspire and guide the establishment of the students found that the awareness of the problem and thinking problems, encourage independent learning, students design and the practical ability to improve the overall quality of students, making socially useful design talent.

\section{References}

[1] Yin Chuanrong the current orientation of the higher design education and future significance. Art and Design, 2011, 2 (82):172-173.

[2] Chen turned clear, sand strong culture of industrial design engineering students design capability . Art and Design, 2011, 2 (83):187-189.

[3] Pan Zhao Nan design new ideas . Hunan: Hunan Fine Arts Publishing House, 2003:18-25.

[4] Beautiful seats, repair candle, new. Discussion science to help improve students' ability to analyze problems . Extracurricular education in China, 2012, 408:68-69

[5] Liu Ruizhi. Inquiry-based teaching model research . Dalian: Liaoning Normal University, a master's degree thesis, 2005.

[6] MaZhen. PBL teaching mode in Chinese universities graduate teaching Applied Research . Jinan: Shandong Normal University, a master's degree thesis, 2011.

[7] Qin Zan. College of Art and Design education in teaching mode explore . Shijiazhuang: Hebei Normal University, a master's degree thesis, 2008.

[8] Zhang Cuimin. Studio teaching model applied research in university industrial design professional . Shenyang: Shenyang Normal University, a master's degree thesis, 2012.

[9] Xiaorong Zhu. On Art Design Education from the Angle of Culture .Art and Design, 2011, 9 (83):184-186.

[10] Xiaorong Zhu.On Current Problems of Art Design Education . Art and Design, 2011, 8(82):170-171. 